\title{
The Effect of Engineering Summer Camps on Middle School Students Inter- est and Identity
}

\author{
Dr. Indira Chatterjee, University of Nevada, Reno
}

Indira Chatterjee received her M.S. in Physics from Case Western Reserve University, Cleveland, Ohio in 1977 and Ph.D. in Electrical Engineering from the University of Utah, Salt Lake City, Utah in 1981. Indira is Associate Dean of Engineering and Professor of Electrical and Biomedical Engineering at the University of Nevada, Reno. As Associate Dean she oversees undergraduate and graduate education in the college including assessment, accreditation, recruitment, retention and advising. She also coordinates efforts to expand the research productivity of the College of Engineering. This includes promoting and facilitating industry-college partnerships, identifying and monitoring opportunities for competitive research grants, apprising faculty of research opportunities and providing coordination and leadership for forming research teams as needed to respond to these opportunities. She serves as chair of the College of Engineering curriculum committee and is a member of the university curriculum committee. Indira has been a faculty member at the University of Nevada, Reno since 1988. As Professor of Electrical and Biomedical Engineering she has been actively involved in funded research. She has been primary mentor to several graduate students who are well placed in industry and academics. Her research areas include: Numerical and experimental bioelectromagnetics, $\mathrm{RF} /$ microwave/millimeter wave dosimetry, high intensity electronanopulse clinical applications, antenna design, and electrical properties of materials. Over the past 20 years she has brought in over $\$ 5$ million in research funding from the Department of Defense Johns Hopkins University, National Institutes of Health, Environmental Protection Agency, Department of Energy and GE Energy. She is a senior member of the IEEE, a member of the IEEE MTT-10 committee, and a member of the ASEE, Bioelectromagnetics Society and Society of Women Engineers. She serves on the editorial board of the Bioelectromagnetics Society.

\section{Dr. Adam Kirn, University of Nevada, Reno}

Adam Kirn is an Assistant Professor of Engineering Education at University of Nevada, Reno. His research focuses on the interactions between engineering cultures, student motivation, and their learning experiences. His projects involve the study of student perceptions, beliefs and attitudes towards becoming engineers, their problem solving processes, and cultural fit. His education includes a B.S. in Biomedical Engineering from Rose-Hulman Institute of Technology, a M.S. in Bioengineering and Ph.D. in Engineering and Science Education from Clemson University.

\section{Dr. Jennifer R Amos, University of Illinois, Urbana-Champaign}

Dr Amos joined the Bioengineering Department at the University of Illinois in 2009 and is currently a Teaching Associate Professor in Bioengineering and an Adjunct Associate Professor in Educational Psychology. She received her B.S. in Chemical Engineering at Texas Tech and Ph.D. in Chemical Engineering from University of South Carolina. She completed a Fulbright Program at Ecole Centrale de Lille in France to benchmark and help create a new hybrid masters program combining medicine and engineering and also has led multiple curricular initiative in Bioengineering and the College of Engineering on several NSF funded projects. 


\section{The Effect of Engineering Summer Camps on Middle School Students Interest and Identity}

\section{Introduction}

A persistent problem in engineering is an insufficient number of students interested in pursuing engineering as a college major and career. Under enrollment in engineering is highest for underrepresented groups [1]. Student interest in engineering at the K-12 level has been shown to predict whether students of all backgrounds pursue engineering as a college major and career [2, 3]. Middle school is a critical time where student interest, identity, and career choices begin to solidify $[4,5]$. Social cognitive scientists [6, p. 79] have developed a framework based on social cognitive theory [7] for understanding three factors that are critical in career pathway development in late adolescents and early adulthood, namely, "(1) Formation and elaboration of career-relevant interests, (2) Selection of academic and career choice options, and (3) Performance and persistence in educational and occupational pursuits". They also point out that social and economic factors affect the level and content of career choices.

The National Academy of Engineering and National Research Council emphasize the importance of engineering education at the K-12 level [8]. Since states have been slow to adopt the NGSS (Next Generation Science Standards) and to include engineering curricula in their K12 classrooms $[9,10]$, many universities with engineering programs have implemented informal STEM outreach programs for students in elementary, middle and high schools. However, there is a need for a better understanding of the ways in which these outreach programs influence middle school students choice of engineering as a major and career. Specifically, "Increasing the interest of K-12 students in the sciences rests on university outreach efforts and improved K-12 instruction" [4, p. 6]. This report as well as [5] point to middle school age as the critical age when students start forming interest in careers and hence the population on which studies should focus. There is a need to better understand the ways in which outreach programs like engineering summer camps influence engineering interest and identity in middle school students and subsequent choice of engineering as a major and career.

To develop engineering-specific theories of how engineering identities are formed, this paper describes the methodological plan for understanding interest and identity development of three middle-school populations participating in engineering summer camps offered by the College of Engineering at the University of Nevada, Reno, NV: (1) women in engineering (2) first generation students and, (3) open-enrollment engineering camps. The research design leverages existing quantitative surveys along with focus groups and observations based on a selected set of questions from these surveys.

\section{Research Design, Methods and Instruments}

The research design for this project is based on guidelines provided by Creswell [11]. Specifically, a convergent parallel mixed methods approach will be utilized in this study. The research questions that will be addressed are: (1) How strongly are engineering identity and interest linked to the pursuit of engineering as a major in college and as a possible future career? (2) Which specific activities in the summer camps lead to a change in identity and interest in engineering? (3) To what extent and in what ways do the qualitative participant focus group 
interviews and observations of participants engaged in camp activities contribute to a comprehensive understanding of the quantitative data obtained via pre- and post-surveys?

\section{Description of summer camps/participants}

Three summer camps are the focus of this project. They each cater to different middle school populations: The Young Women in Engineering camp is all female; the First-Generation camp is for students who will be the first person in their immediate family to attend college and the Introduction to Engineering (Open-Enrollment) camp admits any student who applies on a firstcome first-served basis.

The camps are identical in content and designed with the goal of increasing understanding of different engineering fields and careers. The only difference between the three camps is that the women-focused and first-generation camps involve participation of guest speakers and role-model mentors appropriate for the camp populations. The camp activities include building an electric speaker, blasting off bottle rockets, testing self-made towers on a miniature shake table, and visiting a local engineering company. Field trips and campus tours introduce students to local engineering landmarks and engineering companies. University faculty and graduate students lead camp sessions. Camp information is disseminated to students through e-mails to teachers, campus supporters, and mail flyers to middle and high school mathematics and science teachers. The three camps are extremely popular and have filled up quickly since they have been offered. The goal is to have 25 students in each camp participating in the research study. Thus, there will be 75 participants in each year of the two-year study with a total of 150 participants. The following is a description of the three camps:

Introduction to Engineering Camp: introduces students to various engineering disciplines through fun, age-appropriate activities. The intent of the camp is to develop the students' curiosity in Engineering and promote a lifelong interest in the field.

Young Women in Engineering Camp: is designed for young women only and introduces them to engineering including lessons, hands-on activities, and mentoring from professional female engineers, university faculty, alumni, and current engineering students. At the end of the camp, students attend a mentoring luncheon with local female engineering professionals. Students mingle and interact with many of the top female engineers in Reno.

First Generation Engineering Camp: is a free, introductory camp which is open only to students who will be the first person in their immediate family to attend college. Students attend a luncheon with guest speakers from minority-serving university organizations.

\section{Plan for data collection:}

The project will proceed in one phase with two data streams. Quantitative data will be gathered in Phase 1 that will be done twice, first when students register for the summer camp (pre-survey) and the second at the end of the summer camp (post-survey). The survey questions will be from the Friday Institute survey [12], an instrument that has been tested and validated [13]. Qualitative data in the form of in-depth focus group interviews (on day 5/5) with 7 - 8 participants per focus group and observations of camp activities during the five days of the summer camp will be implemented. The semi-structured focus group protocol will use the same constructs as the quantitative data collection. The open-ended focus group questions will be a select subset of the questions on the pre- and post- surveys. Observations of participants involved in camp activities 
will also use a semi-structured checklist based on this subset of questions. The focus group interviews will be digitally recorded and transcribed.

\section{Grounded Theory}

The qualitative analysis will utilize Grounded Theory [14 - 16]. The steps included in the qualitative data analysis are: (1) Organizing and preparing the data, i.e. transcribing the focus group interviews and observations of camp activities, and typing up the notes taken during observations; (2) Reading all the data to obtain a sense of what general responses the participants are giving and the tone in which they are given; (3) Coding of the data, i.e. organizing the data by segments and deciding on a descriptive word to represent a topic category; (4) Alphabetizing of the codes; (5) Developing a preliminary codebook; (6) Using the codes for generating five to seven themes that will eventually be the findings of the research; (7). Developing a narrative to describe the findings of the analysis with figures and tables; (8) Interpreting the results.

\section{Conclusions and future work}

The data gathered from the convergent parallel mixed methods approach used in this research project and the resulting grounded theory analysis of three different populations of middle school students participating in engineering summer camps, will address the relationship of engineering identity and interest to pursuit of engineering as a major in college and a possible future career. Moreover, the project will also identify engineering camp activities that lead to changes in identity and interest in engineering for these three populations of middle school students. It is planned as future work to follow up on whether the students participating in the study do choose engineering in college.

\section{Acknowledgement}

This research is funded by the National Science Foundation PFE: RIEF program, grant number EEC - 1738141. The Institutional Review Board of the University of Nevada, Reno has approved all procedures.

\section{References}

1. B.L. Yoder. Engineering by the numbers. 2016. https://www.asee.org/documents/papers-andpublications/publications/college-profiles/16Profile-Front-Section.pdf.

2. L.S. Hirsch, J.D. Carpinelli, H. Kimmel, R. Rockland and J. Bloom, "The differential effects of pre-engineering curricula on middle school students' attitudes to and knowledge of engineering careers", $37^{\text {th }}$ ASEE/IEEE Frontiers in Education Conference Proceedings, October 10-13, 2007, Milwaukee, WI, S2B-18.

3. M-I. Carnasciali, A.E. Thompson and T.J. Thomas, "Factors influencing students' choice of engineering major", 120 ${ }^{\text {th }}$ ASEE Annual Conference \& Exposition Proceedings, 2013.

4. J. Fairweather, "Linking evidence and promising practices in Science, Technology, Engineering and Mathematics (STEM) undergraduate education", A status report for the National Academies National Research Council Board of Science Education, https://nsf.gov/attachments/117803/public/Xc-Linking_Evidence--Fairweather.pdf 
5. STEM Perceptions: Student \& Parent study, Harris Interactive, https://news.microsoft.com/download/archived/presskits/citizenship/docs/STEMPerceptionsRep ort.pdf

6. R.W. Lent, S.D, Brown and G. Hackett, "Toward a unifying social cognitive theory of career and academic interest, choice, and performance", Journal of Vocational Behavior, Vol. 45, pp. 79-122, 1994.

7. A. Bandura. Social foundations of thought and action: A social cognitive theory, Englewood Cliffs, NJ: Prentice-Hall, 1986.

12. T.J. Moore, K.M. Tank, A.W. Glancy and J.A. Kersten, "NGSS and the landscape of engineering in K12 state science standards", Journal of Research in Science Teaching, Vol. 52, pp. 296 - 318, 2015.

13. R.L. Carr, L.D. Bennett IV, J. Strobel, "Engineering in the K-12 STEM standards of the 50 U.S. States: An analysis o presence and extent", Journal of Engineering Education, Vol. 101, pp. 539 - 564, 2012.

11. J, W. Creswell. Research Design. Qualitative, Quantitative and Mixed Methods Approaches. $4^{\text {th }}$ Edition, Sage Publications, Inc. Thousand Oaks, CA, 2014.

12. Friday Institute for Educational Innovation. Student Attitudes toward STEM Survey-Middle and High School Students, Raleigh, NC: Author. 2012

13. A. Unfried, M. Faber and E. Wiebe, "Gender and student attitudes toward Science, Technology, Engineering, and Mathematics", http://miso.ncsu.edu/wpcontent/uploads/2014/08/AERA-2014-paper-Student-Attitudes-Toward-STEM.pdf

14. J. Corbin and A. Strauss, "Grounded theory research: Procedures, Canons, and evaluative criteria”, Qualitative Sociology, Vol. 13, No. 1, 1990, pp. 3 -21.

15. K. Charmaz. Constructing Grounded Theory. A practical guide through qualitative analysis. Sage Publications, Thousand Oaks, 2006.

16. N.V.N. Chism, E. Douglas and W.J. Hilson, Jr. Qualitative Research Basics: A guide for engineering educators. Rigorous Research in Engineering Education, NSF DUE-0341127, 2008. 